\title{
MANEJO DA AVEIA PRETA NA DECOMPOSIÇÃO DA BIOMASSA E NA COBERTURA DO SOLO EM SEMEADURA DIRETA DE MILHO
}

\section{MANAGEMENT OF BLACK OAT ON BIOMASS DECOMPOSITION AND SOIL COVER UNDER NO-TILLAGE SYSTEM OF MAIZE}

\author{
José Alfredo Batista dos SANTOS ${ }^{1}$ \\ Jadir Aparecido ROSA ${ }^{2}$ \\ Dácio Antonio BENASSI ${ }^{3}$ \\ Altair JUSTINO ${ }^{4}$
}

\begin{abstract}
RESUMO
Com o objetivo de avaliar a decomposição e o índice de cobertura de aveia preta (Avena strigosa Schreb) em sucessão com milho (Zea mays L.) em semeadura direta, foi conduzido um experimento no período de julho de 2006 a abril de 2007, no município de Ponta Grossa, PR. O delineamento experimental utilizado foi de blocos ao acaso com parcelas subdivididas e quatro repetições. Os tratamentos principais foram os métodos mecânicos de manejo: rolo-faca antes do plantio, rolo-faca pós-plantio, roçadora e triturador, enquanto que os tratamentos secundários foram com e sem dessecação. Avaliou-se o índice de cobertura da aveia e a produção de biomassa seca ao longo do ciclo da cultura do milho. As taxas de decomposição da aveia preta e índices de cobertura diferiram estatisticamente apenas na segunda avaliação (22 dias após semeadura do milho). $\mathrm{O}$ rendimento de grãos de milho não apresentou diferenças estatísticas para os métodos testados.
\end{abstract}

Palavras-chave: Avena strigosa; Zea mays; dessecação; resíduos culturais.

\begin{abstract}
With the objective of evaluating the decomposition and soil cover of black oat (Avena strigosa Schreb) in succession with maize (Zea mays L.) in no-tillage system, it was installed an experiment in Ponta Grossa PR, Brazil. The experiment was laid out as random block design with split-plot and four replications. The main treatments were composed by four mechanical management systems of oat ( knife-rolled before and after seeding of maize, shredder and chopper) set up in $14.4 \times 6 \mathrm{~m}$ plots. The split-plot $(7.2 \times 6 \mathrm{~m})$ treatments were with and without chemical desiccation with glyphosate. It was evaluated the index of cover of the oat and the output of dry biomass throughout the cycle of the culture of the maize. The rates of decomposition of the black oat and index of soil cover had differed statistically only in the second evaluation (22 days after seeding of the maize). Maize grain yield in succession to oat was not influenced by management systems of oat straw.
\end{abstract}

Key-words: Avena strigosa; Zea mays, desiccation; crop residues.

\footnotetext{
${ }^{1}$ Mestre em Agronomia pela Universidade Estadual de Ponta Grossa e Profissional de Ciência e Tecnologia do IAPAR, Unidade Regional de Pesquisa Centro-Sul. E-mail: jose_alfredo@iapar.br

2 Eng. Agrícola, Ph. D., Pesquisador do IAPAR, Unidade Regional de Pesquisa Centro-Sul, Ponta Grossa - PR, Caixa postal 129, Ponta Grossa - PR, CEP 840001-970. E-mail: jrosa@iapar.br. Autor para correspondência.

${ }^{3}$ Mestre em Agronomia pela Universidade Estadual de Ponta Grossa e Profissional de Ciência e Tecnologia do IAPAR, Unidade Regional de Pesquisa Centro-Sul. E-mail: dacio_benassi@iapar.br

${ }^{4}$ Professor Associado do Departamento de Ciências do Solo e Eng. Agrícola, Universidade Estadual de Ponta Grossa. E-mail: ajustino@uepg.br
} 


\section{INTRODUÇÃO}

$\mathrm{Na}$ semeadura direta, a palhada ou restos vegetais de culturas remanescentes permanecem sobre a superfície do solo, propiciando um microclima favorável ao desenvolvimento das culturas em sucessão. Este sistema se pauta em práticas de rotação de culturas, plantio de cobertura verde de inverno e supressão da mobilização do solo. Proteger o solo por cobertura vegetal (viva ou morta) é um requisito-chave para a melhoria do solo no sistema plantio direto (SPD), pelo aumento da biodiversidade e do equilíbrio ambiental no sistema soloplanta (Muzilli, 2006). Entre os benefícios da cobertura vegetal no SPD incluem-se o controle da erosão, a conservação da água no solo, a reciclagem de nutrientes e a supressão de plantas daninhas.

Para o sucesso do sistema de semeadura direta, é importante a escolha correta da espécie invernal para cobertura do solo. Segundo Calegari (2006), a espécie escolhida deve ser adaptada as condições climáticas locais, ser resistente às pragas e doenças, ter desempenho satisfatório na cobertura do solo e na supressão de plantas daninhas, e boa produção de massa verde e seca, entre outros atributos.

Segundo Araújo \& Rodrigues (2000), manter o solo coberto pelo maior período possível favorece a consolidação da cultura subseqüente, pois ameniza os impactos diretos das intempéries. O conhecimento da taxa de decomposição das coberturas de inverno possibilita planejar cultivos e práticas conservacionistas pela permanência da biomassa e seus benefícios sobre a superfície do solo (Bertol et al., 1998).

Diversos pesquisadores apresentaram os efeitos benéficos das plantas de cobertura nas propriedades do solo e no rendimento das culturas, pela produção de fitomassa, acúmulo e liberação de nutrientes pela decomposição da biomassa (Amado et al., 2002; Rosolem et al., 2003; Gama-Rodrigues et al., 2007).

A adoção da rotação de culturas no período de entressafra, principalmente no inverno, é fator positivo para a consolidação de uma agricultura sustentável (Chaves \& Calegari, 2001). A aveia preta é a espécie mais utilizada como cobertura de inverno no sul do Brasil, antecedendo ao milho em semeadura direta. Este fato está ligado ao seu elevado potencial de produção de biomassa, baixo custo na produção, facilidade na aquisição de sementes, rusticidade, rapidez na cobertura do solo e fácil manejo (Da Ros \& Aita, 1996; Biazi et al., 2007), além da baixa taxa de decomposição, protegendo o solo por mais tempo (Bortolini et al., 2000). A aveia preta possui também elevado efeito supressor/alelopático sobre plantas daninhas, reduzindo custos com capinas mecânica ou química (Calegari, 2006).

Resultados de Alvarenga et al. (2001), apontam produção de $6 \mathrm{t} \mathrm{ha}^{-1}$ de matéria seca so- bre a superfície do solo, como suficiente para realização de cultivo conservacionista, pela boa proteção do solo.

O manejo da cobertura de inverno deve ser realizado de modo a não causar problemas operacionais na semeadura e infestações de plantas daninhas, prejudicando o estabelecimento das culturas principais. A decisão de apenas acamar ou cortar a palha, associado ou não com herbicidas, deve ser analisada conforme as necessidades do produtor, adotando-se o método e o momento mais adequado para o manejo (Casão Júnior \& Siqueira, 2006).

No manejo mecânico da cultura da cobertura de aveia preta, os equipamentos mais utilizados são: rolo-faca, triturador de restos vegetais, roçadora e grade de discos. Segundo Araújo \& Rodrigues (2000), o manejo mecânico tem eficiência comprovada apenas quando realizado no estádio correto de desenvolvimento da aveia, que é a fase de grãos leitosos, quando a produção de massa vegetal atinge o máximo e o índice de rebrota é reduzido. Já a eficiência do manejo químico depende menos do estádio da planta, possibilitando seu emprego em várias situações. Em algumas espécies, a quantidade de massa vegetal poderá influenciar na recomendação da dosagem para a sua dessecação e controle das plantas daninhas antes da semeadura, para que a cultura tenha desenvolvimento inicial livre de interferências (Timossi et al. 2006).

Neste trabalho, o objetivo foi avaliar a decomposição e o índice de cobertura de aveia preta (Avena Strigosa Schreb) em sucessão com milho (Zea mays L.) em semeadura direta.

\section{MATERIAL E MÉTODOS}

O experimento foi conduzido na Estação Experimental do IAPAR em Ponta Grossa - PR, cujas coordenadas geográficas são: latitude $25^{\circ} 05^{\prime}$ $\mathrm{S}$, longitude $50^{\circ} 09^{\prime} \mathrm{W}$ e uma altitude média de 840 $\mathrm{m}$. O clima da região, na classificação climática de Köppen, é Cfb, sendo que o solo é classificado como Latossolo Vermelho Distrófico textura argilosa (Bhering \& Santos 2008).

O delineamento experimental utilizado foi de blocos ao acaso, com parcelas subdivididas, com quatro repetições. As parcelas foram constituídas de $14,4 \mathrm{~m}$ de comprimento por $6 \mathrm{~m}$ de largura, e as subparcelas de $7,2 \mathrm{~m}$ de comprimento por 6,0 $\mathrm{m}$ de largura.

Os tratamentos principais foram os métodos mecânicos de manejo: T1 - rolo-faca antes do plantio, T2 - rolo-faca pós-plantio, T3 - roçadora e T4 - triturador de restos vegetais. O rolo-faca era constituído por um cilindro metálico com 2,05 m de circunferência, largura de $1,50 \mathrm{~m}$, com facas dispostas a cada $0,20 \mathrm{~m}$, com afiação em bisotê, acoplado na barra de tração do trator. A roçadora era da marca MF, com largura de $1,60 \mathrm{~m}$, acoplada aos três pontos do trator e acionada pela tomada de poten- 
SANTOS, J.A.B. dos et al. Manejo da aveia preta...

cia a $540 \mathrm{rpm}$. O triturador era do modelo triton, com $1,80 \mathrm{~m}$ de faixa de corte, acoplado aos três pontos do trator, acionado por tomada de potência a $540 \mathrm{rpm}$, com facas em sistema rotativo. As subparcelas constituíram do uso ou não de dessecante químico (tratamentos secundários).

A cultivar utilizada de aveia preta foi a IAPAR 61 que foi semeada em meados de julho de 2006, com densidade de $50 \mathrm{~kg} \mathrm{ha}^{-1}$ e espaçamento de $0,17 \mathrm{~m}$, e em cobertura foi aplicado $45 \mathrm{~kg}$ de $\mathrm{N}$ ha $^{-1}$ utilizando-se como fonte a uréia, no estádio de perfilhamento (26 dias após a emergência).

O manejo mecânico foi realizado quando a aveia atingiu o estádio de grão leitoso, buscando-se o mínimo de rebrotes. As operações foram realizadas do centro para as laterais dos blocos, tombando as plantas na mesma posição para todos os tratamentos, permitindo a semeadura do milho no sentido transversal ao manejo.

No manejo químico utilizou-se glyphosate na dose $0,960 \mathrm{~kg} \mathrm{ha}^{-1}$, aplicado no estádio de pleno florescimento da aveia preta, vinte dias antes do estádio de grãos leitosos, época em que foram realizados os manejos mecânicos. A aplicação foi realizada com pulverizador de barras acoplado ao trator, observando técnicas de aplicação (Ramos \& Pio, 2003).

A semeadura do milho, cultivar IPR 114, foi realizada em 22/11/2006, com espaçamento de $0,90 \mathrm{~m}$ entre linhas e população de 60.000 plantas ha ${ }^{-1}$. A adubação na base foi de $300 \mathrm{~kg} \mathrm{ha}^{-1}$ de $08-$ $30-20$, e em cobertura, $100 \mathrm{~kg}$ de ureia ha ${ }^{-1}$ no estádio de quatro a seis folhas. Os demais tratos culturais seguiram recomendações regionais.

A matéria seca da aveia foi avaliada coletando-se três amostras de $0,25 \mathrm{~m}^{2}$ por parcela, utilizando-se um quadro de madeira de $0,50 \mathrm{~m}$ de lado lançado ao acaso na parcela, aos $0,22,53,86$ e 147 dias após a semeadura do milho. As amostras foram secas em temperatura de $60^{\circ} \mathrm{C}$ por 72 horas, conforme procedimento descrito por Miyazawa et al. (1992).

Avaliou-se também a biomassa de culturas de safras anteriores, milho e soja, nos anos de 2004/2005 e 2005/2006 respectivamente, resultando em $1,4 \mathrm{Mg} \mathrm{ha}^{-1}$, sendo $65 \%$ de resíduos do miIho e $35 \%$ de resíduos da soja. Esta avaliação foi realizada na área total do experimento, apenas para apontar a importância da rotação de culturas na proteção do solo em cultivos subseqüentes, corroborando com as informações de Sodré Filho et al. (2004) que citam o plantio direto como sistema que proporciona maior acúmulo de biomassa ao solo pelas culturas de sucessão.

0 índice de cobertura do solo pela aveia preta foi realizado aos $0,22,53$ e 86 dias após a semeadura (DAS), medidos com uso de fio com 5,0 $\mathrm{m}$, graduado a cada $0,10 \mathrm{~m}$ e colocados sobre o solo de forma cruzada. A avaliação foi realizada com visada perpendicular ao solo, observando os pontos protegidos pela biomassa, conforme metodologia descrita por Laflen et al. (1981).
No final do ciclo do milho, foram colhidas duas linhas centrais de cada subparcela, com 5,0 m de comprimento, desprezando-se $0,50 \mathrm{~m}$ em cada extremidade, para avaliação do rendimento. As espigas foram despalhadas e debulhadas em debuIhador manual, pesadas em balança de precisão, determinando sua umidade, e corrigindo para umidade de $13 \%$, teor considerado padrão para armazenagem de milho (Pimentel et al., 1988).

A análise estatística dos resultados foi feita com o programa computacional SAS, com médias comparadas pelo teste de Tukey a $5 \%$ de probabilidade.

\section{RESULTADOS E DISCUSSÃO}

Taxa de decomposição da biomassa de aveia preta

Os resultados de produção de biomassa entre os tratamentos não apresentaram diferenças significativas, resultado da influência do alto rendimento de biomassa da aveia preta $\left(7,5 \mathrm{Mg} \mathrm{ha}^{-1}\right)$, superior a $6,0 \mathrm{Mg} \mathrm{ha}^{-1}$ sugerida por Alvarenga et al. (2001) como adequada à uma boa cobertura do solo. Altas produções de biomassa são obtidas com boa fertilidade, e condições climáticas, edáficas e fitossanitárias adequadas (Amado et al., 2002).

$\mathrm{Na}$ avaliação no dia da semeadura do milho (0 DAS), ocasião da realização dos manejos mecânicos, não foram observadas diferenças estatísticas significativas, tanto para os métodos mecânicos de manejo com ou sem dessecação química (Tabela 1). Esses resultados sugerem que a dessecação da aveia preta no florescimento pleno não afeta de imediato a decomposição, em relação à subparcela que permanece vegetando até o estádio de grãos leitosos. Para Ahrens (1994), a ação sistêmica do glyphosate provoca morte lenta das plantas, podendo retardar a degradação da palha, compensando o tempo de permanência no campo do tratamento sem herbicida e o possível acúmulo de biomassa.

$\mathrm{Na}$ segunda avaliação (22 DAS), os manejos com rolo-faca antes e depois da semeadura não diferiram estatisticamente, mas foram superiores aos demais na avaliação de permanência de biomassa sobre o solo (Tabela 1). Estes resultados sugerem tratar-se do efeito da fragmentação da biomassa da aveia preta pelo triturador e roçadora acelerando a decomposição (Araújo \& Rodrigues, 2001) pela produção de fragmentos pequenos (50 e $150 \mathrm{~mm}$ ). A decomposição é favorecida pelo contato dos fragmentos com o solo, no que se enquadram a roçadora e o triturador (Douglas et al., 1980), além da umidade e temperatura do ar (Bertol et al., 1998). Derpsch et al. (1991), citam que equipamentos de manejo apresentam resultados variados pela fragmentação e deposição sobre o solo, determinante na taxa de decomposição da biomassa.

O melhor resultado do rolo- faca sobre os demais equipamentos, de certa forma justifica a predileção dos agricultores familiares do Centro-Sul do Paraná pelo uso deste método de manejo, sob 
SANTOS, J.A.B. dos et al. Manejo da aveia preta...

TABELA 1 - Avaliações de massa seca da cobertura de aveia preta $\left(\mathrm{Mg} \mathrm{ha}^{-1}\right)$ durante a condução da cultura do milho. Ponta Grossa, PR, 2006-2007.

\begin{tabular}{|c|c|c|c|c|c|c|c|c|c|c|c|c|c|c|c|}
\hline \multirow{3}{*}{$\begin{array}{l}\text { Man. } \\
\text { Mec. }\end{array}$} & \multicolumn{15}{|c|}{ DIAS APÓS SEMEADURA DO MILHO (DAS) } \\
\hline & \multicolumn{3}{|c|}{ 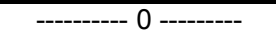 } & \multicolumn{3}{|c|}{ 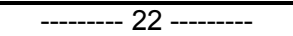 } & \multicolumn{3}{|c|}{ 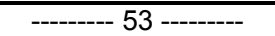 } & \multicolumn{3}{|c|}{ 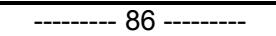 } & \multicolumn{3}{|c|}{ 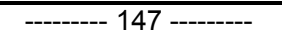 } \\
\hline & $\mathrm{CH}$ & $\mathrm{SH}$ & Média & $\mathrm{CH}$ & $\mathrm{SH}$ & Média & $\mathrm{CH}$ & $\mathrm{SH}$ & Média & $\mathrm{CH}$ & $\mathrm{SH}$ & Média & $\mathrm{CH}$ & $\mathrm{SH}$ & Média \\
\hline RFAP & 7,51 & 5,62 & $6,57 \mathrm{~A}$ & 6,59 & 5,08 & $5,84 A$ & 3,63 & 2,75 & $3,19 \mathrm{~A}$ & 1,63 & 1,74 & $1,69 \mathrm{~A}$ & 1,43 & 1,30 & $1,36 \mathrm{~A}$ \\
\hline RFPP & 6,58 & 6,17 & 6,38A & 5,85 & 4,41 & 5,13AB & 3,42 & 2,60 & $3,01 \mathrm{~A}$ & 1,56 & 2,15 & $1,85 \mathrm{~A}$ & 1,37 & 1,46 & $\overline{1,41 A}$ \\
\hline Roç. & 5,48 & 5,41 & $5,45 A$ & 4,82 & 3,54 & 4,18BC & 4,50 & 2,66 & $3,58 \mathrm{~A}$ & 1,92 & 2,25 & $2,09 \mathrm{~A}$ & 1,70 & 1,73 & $1,72 \mathrm{~A}$ \\
\hline Trit. & 6,09 & 6,67 & $6,38 \mathrm{~A}$ & 3,98 & 3,80 & $3,88 \mathrm{BC}$ & 2,88 & 2,56 & $2,72 A$ & 1,76 & 2,12 & $1,94 \mathrm{~A}$ & 1,55 & 1,36 & $\overline{1,46 A}$ \\
\hline Média & $6,41 \mathrm{a}$ & $5,96 a$ & & $5,31 a$ & $4,20 b$ & & $3,61 a$ & $2,64 a$ & & $1,72 a$ & $2,06 a$ & & $1,51 a$ & $1,46 a$ & \\
\hline $\mathrm{CV}(\%)$ & & & 29,1 & & & 29,9 & & & 37,4 & & & 17,7 & & & 19,6 \\
\hline
\end{tabular}

Manejos mecânicos: RFAP: rolo faca antes do plantio; RFPP: rolo faca pós plantio; Roç.: roçadora; Trit.: triturador. $\mathrm{CH}$ : manejo com herbicida; SH: manejo sem herbicida. Médias seguidas pela mesma letra maiúscula nas colunas (manejos mecânicos da aveia na mesma data de avaliação) e médias seguidas pela mesma letra minúscula na linha (manejos químicos da aveia na mesma data de avaliação) não diferem entre si pelo Teste de

Aos 22 dias após a semeadura, os tratamentos com dessecação química (secundários) foram estatisticamente superiores (Tabela 1), sugerindo a inter-relação com a morte lenta das plantas de cobertura pelo herbicida não seletivo, citado por Ahrens (1994). Esse resultado contraria a hipótese de que dessecação química seguida de manejo mecânico estimularia o processo de decomposição da biomassa (Roman \& Velloso, 1993; Araújo \& Rodrigues, 2000); contudo, esses autores citam o herbicida de contato com morte abrupta e instantânea das plantas.

Por outro lado, Victória et al (1992) destacam que o padrão de decomposição dos resíduos se dá em duas fases: na primeira fase, ocorre rápida decomposição dos carboidratos simples, amido, açúcares e proteínas, enquanto na segunda fase há decomposição dos materiais com relação $\mathrm{C} / \mathrm{N}$ mais altas, como celulose, gorduras, ceras, taninos e ligninas, fazendo com que a relação $\mathrm{C} / \mathrm{N}$ dos resíduos aumente.

Nas avaliações realizadas aos 53, 86 e 147 dias após a semeadura do milho os valores de biomassa seca não diferiram estatisticamente, tanto para os tratamentos principais (métodos mecânicos de manejo) quanto para os secundários (com ou sem dessecação). A ultima avaliação realizada em 18/04/07 (147 DAS), com a cultura do milho em ponto de colheita, a biomassa de aveia preta constituía-se apenas de materiais fibrosos. Este resultado sugere uma estabilização na taxa de decomposição após certo período (Biazi et al., 2007), pela permanência da parte da aveia com maior teor de lignina (Van Soest, 1982) que é o constituinte de mais difí- cil degradação (Chen, 2003).

Índice de cobertura do solo pela biomassa de aveia preta

Para os tratamentos secundários (com ou sem dessecação química), foi observado diferença pela análise estatística, onde os tratamentos com dessecação química tiveram resultados inferiores aos sem dessecação (Tabela 2).

Os resultados de índice de cobertura do solo obtidos na primeira e segunda avaliação (0 e 22 DAS), para métodos mecânicos de manejo, o uso de rolo- faca antes do plantio, rolo- faca pósplantio e triturador não diferiram pela análise estatística. Contudo, o método de manejo com roçadora foi inferior ao rolo- faca pós-plantio. A menor proteção do solo no método de manejo com roçadora corrobora os dados de Derpsch et al. (1991), que citam os diferentes resultados produzidos em função do uso de equipamentos distintos, bem como suas interferências no índice de proteção em função da fragmentação e forma de deposição da biomassa sobre a superfície do solo.

O resultado obtido com o manejo do rolofaca confirma as informações de Reis et al. (2007) e Bortoluzzi \& Eltz (2001), que citam que este equipamento apenas secciona o caule da aveia, mantendo a distribuição da planta inteira sobre o solo, o que proporciona bom nível de cobertura. Assim, a semeadura sobre aveia com uso de rolo- faca proporciona redução na infestação de plantas daninhas pela melhoria na cobertura do solo (Ruedell, 1995). 
SANTOS, J.A.B. dos et al. Manejo da aveia preta...

TABELA 2 - Avaliação do índice de cobertura do solo pela biomassa da aveia preta durante a condução da cultura do milho. Ponta Grossa, PR, 2006-2007.

\begin{tabular}{|c|c|c|c|c|c|c|c|c|c|c|c|c|}
\hline \multirow{2}{*}{$\begin{array}{c}\text { Mane- } \\
\text { jo } \\
\text { mecân } \\
\text { ico }\end{array}$} & \multicolumn{9}{|c|}{ DIAS APÓS SEMEADURA DO MILHO (DAS) } \\
\cline { 2 - 12 }$y$ & CH & SH & Média & CH & SH & Média & CH & SH & Média & CH & SH & Média \\
\hline RFAP & 93,8 & 92,3 & $93,1 \mathrm{AB}$ & 92,5 & 96,5 & $94,5 \mathrm{AB}$ & 92,5 & 95,0 & $93,8 \mathrm{~A}$ & 90,3 & 96,5 & $93,4 \mathrm{~A}$ \\
\hline RFPP & 95,5 & 96,8 & $96,2 \mathrm{~A}$ & 95,5 & 95,8 & $95,7 \mathrm{~A}$ & 94,3 & 94,8 & $94,6 \mathrm{~A}$ & 95,3 & 97,3 & $96,3 \mathrm{~A}$ \\
\hline Roç. & 88,3 & 92,8 & $90,1 \mathrm{~B}$ & 90,5 & 92,8 & $91,7 \mathrm{~B}$ & 88,0 & 94,5 & $91,3 \mathrm{~A}$ & 92,3 & 94,5 & $93,4 \mathrm{~A}$ \\
\hline Trit. & 92,0 & 94,0 & $93,0 \mathrm{AB}$ & 92,3 & 92,0 & $92,2 \mathrm{AB}$ & 91,5 & 93,0 & $92,3 \mathrm{~A}$ & 91,5 & 94,8 & $93,2 \mathrm{~A}$ \\
\hline Média & $92,4 \mathrm{~b}$ & $94,0 \mathrm{a}$ & & $92,7 \mathrm{~b}$ & $94,2 \mathrm{a}$ & & $91,6 \mathrm{~b}$ & $94,3 \mathrm{a}$ & & $92,3 \mathrm{~b}$ & $95,6 \mathrm{a}$ & \\
\hline CV(\%) & & & 6,0 & & & 4,7 & & & 3,6 & & & 4,2 \\
\hline
\end{tabular}

Manejos mecânicos: RFAP: rolo faca antes do plantio; RFPP: rolo faca pós plantio; Roç.: roçadora; Trit.: triturador. $\mathrm{CH}$ : manejo com herbicida; $\mathrm{SH}$ : manejo sem herbicida. Médias seguidas pela mesma letra maiúscula nas colunas (manejos mecânicos da aveia na mesma data de avaliação) e médias seguidas pela mesma letra minúscula na linha (manejos químicos da aveia na mesma data de avaliação) não diferem entre si pelo Teste de Tukey a $5 \%$ de probabilidade. Dados transformados em arc sen $\sqrt{ }(x / 100)$ para análise estatística.

Embora pouco descrito na literatura, rolar a aveia antes e após a semeadura da cultura de verão, são práticas comuns de agricultores familiares que adotam plantio direto com tração animal ou equipamentos de baixa potência no Centro-Sul do Paraná.

Nas avaliações realizadas aos 53 e 86 dias após a semeadura, os índices de cobertura do solo não apresentaram diferenças estatísticas significativas para os métodos mecânicos de manejo (tratamentos principais). Esse resultado é coerente com os dados de biomassa nestas datas, citado no item anterior, e relatado por outros pesquisadores (Biazi et al., 2007; Van Soest, 1982; Chen, 2003).

Para os tratamentos secundários (com ou sem dessecação química), em todas as avaliações realizadas $(0,22,53$ e 86 DAS), os tratamentos sem dessecação química apresentaram resultados superiores aos que receberam dessecação com herbicida, pela análise estatística. Esse resultado de certa forma difere dos obtidos por Victória et al. (1992), que citam o aumento da relação $\mathrm{C} / \mathrm{N}$ da aveia após a dessecação, como relatado anteriormente. Contudo, Victória et al. (1992), referem-se apenas à decomposição logo depois da dessecação, passando por uma normalização com o passar dos dias.

A adoção de um período de 86 dias após a semeadura do milho como base para avaliação final do índice de proteção do solo pela aveia preta (Tabela 2), foi em função de se tratar de período pós-semeadura superior ao período crítico para a cultura do milho, que ocorre entre os estádios fenológicos V2 e V7 (variáveis entre 9 e 41 dias após a emergência da cultura), julgando assim tratar-se de tempo suficiente para que a cultura já tenha definido seu potencial produtivo (Kozlowski, 2002).

Os rendimentos obtidos com o cultivo do milho, tanto para os tratamentos principais (métodos mecânicos de manejo), quanto para os tratamentos secundários (com e sem dessecação química), não apresentaram diferenças significativas pela análise estatística. (Tabela 3 )

\section{CONCLUSÕES}

1) Com relação à taxa de decomposição, os resultados não tiveram grandes variações, entretanto, os manejos com rolo-faca foram mais uniformes durante as avaliações.

2) Para o índice de cobertura, os tratamentos mecânicos foram semelhantes, exceto o manejo com roçadora que se mostrou inferior ao rolo- faca pós-plantio.

3) O rendimento do milho não foi influenciado pelos métodos de manejo mecânicos ou químicos, sugerindo que dependendo do volume de biomassa produzida pela espécie invernal, condições climáticas e nível de infestação de plantas daninhas, o milho pode ser semeado sem a utilização de manejo químico, observando apenas o manejo mecânico seja realizado no estádio de grãos leitosos da aveia. 
SANTOS, J.A.B. dos et al. Manejo da aveia preta...

TABELA 3 - Rendimento de grãos de milho $\left(\mathrm{Mg} \mathrm{ha}^{-1}\right)$ em razão do manejo mecânico e da dessecação da paIhada da aveia preta. Ponta Grossa, 2006/2007.

\begin{tabular}{|c|c|c|c|}
\hline \multirow{2}{*}{ Manejo mecânico } & \multicolumn{2}{|c|}{ Manejo químico } & \multirow{2}{*}{ Média } \\
\cline { 2 - 4 } & Com Herbicida & Sem Herbicida & $\mathbf{7 , 5 4 A}$ \\
\hline Rolo-faca antes do plantio & 7,99 & 7,09 & $\mathbf{7 , 7 4 A}$ \\
\hline Rolo-faca pós-plantio & 8,41 & 7,07 & $\mathbf{7 , 4 2 A}$ \\
\hline Roçadora & 7,56 & 7,28 & $\mathbf{7 , 5 1 A}$ \\
\hline Triturador & 7,89 & 7,12 & 6,65 \\
\hline Média & $\mathbf{7 , 9 6 a}$ & $\mathbf{7 , 1 4 a}$ & \\
\hline CV (\%) & & & \\
\hline
\end{tabular}

Médias seguidas pela mesma letra maiúscula nas colunas (manejos mecânicos da aveia) e médias seguidas pela mesma letra minúscula na linha (manejos químicos da aveia) não diferem entre si pelo Teste de Tukey a $5 \%$ de probabilidade.

\section{REFERÊNCIAS}

1. AHRENS, W. H. Herbicide Handbook. 7.ed. Champaign: Weed Science Society of America, 1994. $352 \mathrm{p}$.

2. ALVARENGA, R. C.; CABEZAS, W. A. L.; CRUZ, J. C.; SANTANA, D. P. Plantas de cobertura de solo para sistema plantio direto. Informe Agropecuário, v. 22, n. 208, p. 25-36, 2001.

3. AMADO, T. J. C.; MIELNICZUK, J.; AITA, C. Recomendações de adubação nitrogenada para milho no RS e SC adaptada ao uso de culturas de cobertura do solo, sob sistema de plantio direto. Revista Brasileira de Ciência do Solo, v.26, n. 1, p. $141-148,2002$.

4. ARAÚJO, A. G.; RODRIGUES, B. N. Manejo mecânico da aveia preta e sua influência sobre a taxa de decomposição e o controle de plantas daninhas em semeadura direta de milho. Planta Daninha. v.18, n. 1, p. 151-160, 2000.

5. BERTOL, I.; CIPRAND, O.; KURSTZ, C.; BAPTISTA, A. S. Persistência dos resíduos de aveia e milho sobre a superfície do solo em semeadura direta. Revista Brasileira de Ciência do Solo, v. 22, n. 4, p. 705-712, 1998.

6. BHERING, S. B.; SANTOS, H. G. dos S. (Eds). Mapa de solos do Estado do Paraná: Legenda atualizada. Rio de Janeiro: Embrapa Florestas: Embrapa Solos: IAPAR, 2008. 74 p.

7. BIAZI, D. GATIBONI, L. C., BIANCHET, F. J., WILDNER, L. P. PAULI, L. Avaliacão da taxa de decomposição de resíduos de aveia e centeio e seu efeito sobre o crescimento de plantas invasoras. In: CONGRESSO BRASILEIRO DE CIÊNCIA DO SOLO, 31., 2007. Anais. Gramado: Sociedade Brasileira de Ciência do Solo, 2007. 1 CD.

8. BORTOLINI, C. G.; SILVA, P. R.; ARGENTA, G. Sistemas consorciados de aveia preta e ervilhaca comum como cobertura de solo e seus efeitos na cultura do milho em sucessão. Revista Brasileira de Ciência do Solo, v. 24, n. 4, p.897-903, 2000.

9. BORTOLUZZI, E. C.; ELTZ, F. L. F. Manejo da palha da aveia preta sobre as plantas daninhas e rendimento de soja em semeadura direta. Ciência Rural, v. 31, n. 2, p.237-243, 2001.

10.CALEGARI, A. Plantas de cobertura. In: CASÃO JÚNIOR, R.; SIQUEIRA, R.; MEHTA, Y. R.; PASSINI, J. J. (Ed.). Sistema plantio direto com qualidade. Londrina: IAPAR; Foz do Iguaçu: ITAIPU Binacional, 2006. p. 55-73.

11.CASÃO JÚNIOR, R.; SIQUEIRA, R. Máquinas para manejo de vegetações e semeadura em plantio direto. In: CASÃO JÚNIOR, R.; SIQUEIRA, R.; MEHTA, Y. R.; PASSINI, J. J. (Ed.). Sistema plantio direto com qualidade. Londrina: IAPAR; Foz do Iguaçu: ITAIPU Binacional, 2006. p. 85-126.

12.CHAVES, J. C. D.; CALEGARI, A. Adubação verde e rotação de culturas. Informe Agropecuário, v. 22, n. 208, p. 53-60, 2001.

13.CHEN, Y. Nuclear magnetic resonance, infra-red and pyrolysis: application of spectroscopic methodologies to maturity determination of composts. Compost Science \& Utilization, v. 11, n. 2, p. 152-168, 2003.

14.DA ROS, A. O.; AITA, C. Efeito de espécies de inverno na cobertura de solo e fornecimento de nitrogênio ao milho em plantio direto. Revista Brasileira de Ciência do Solo, v. 20, n. 1, p.135-140, 1996.

15.DERPSCH, R.; ROTH, C. H.; SIDIRAS, N.; KOPEK, U. Controle de erosão no Paraná, Brasil: sistemas de cobertura do solo, plantio direto e preparo conservacionista do solo. Eschborn: GTZ, 1991. 222 p.

16.DOUGLAS JR, C. L.; ALMARAS, R. R.; RASMUSSEN, P. E.; RAMIG, R. E.; ROAGER JR, N. C. Wheat straw composition and placement effects on decomposition in dryland agriculture of the Pacific northwest. Soil Science Society of America Journal, v. 44, n. 4, p. 833-837, 1980.

17.GAMA-RODRIGUES, A. C.; GAMA-RODRIGUES, E. F.; BRITO, E. C. Decomposição e liberação de nutrientes de resíduos culturais de plantas de cobertura em argissolo vermelho-amarelo na região noroeste fluminense (RJ). Revista Brasileira de Ciência do Solo, v. 31, n. 6, p.1421-1428, 2007.

18.KOZLOWSKI, L. A. Período crítico de interferência das plantas daninhas na cultura do milho baseado na fenologia da cultura. Planta Daninha, v. 20, n. 3, p. 365-372, 2002. 
SANTOS, J.A.B. dos et al. Manejo da aveia preta...

19. LAFLEN, J. M.; AMEMIYA, M.; HINTZ, E. A. Measuring crop residue cover. Journal of Soil and Water Conservation, v. 36, n. 6, p. 341-343, 1981.

20.MIYAZAWA, M.; PAVAN, M. A.; BLOCH, M. F. M. Análise química de tecido vegetal. Londrina: IAPAR, 1992. (Circular, 74).

21.MUZILLI, O. Manejo do solo em sistema plantio direto. In: CASÃO JÚNIOR, R.; SIQUEIRA, R.; MEHTA, Y. R.; PASSINI, J. J. (Ed.). Sistema plantio direto com qualidade. Londrina: IAPAR; Foz do Iguaçu: ITAIPU Binacional, 2006. p. 9-27.

22.PIMENTEL, M. L.; ARAÚJO, M. R. A.; LYRA, M. A.; TABOSA, J. N. Armazenamento do milho a nível de fazenda. Revista Brasileira de Sementes, v.10, n. 3, p. 45-58, 1988.

23.RAMOS, H. H.; PIO, L. C. Tecnologia de Aplicação de Produtos Fitossanitários. In: ZAMBOLIM, L.; MARÇAL, Z. C.; SANTIAGO, T. O que os engenheiros agrônomos devem saber sobre o uso de produtos fitossanitários. Viçosa: UFV, 2003. p. 133-200.

24.REIS, G.N.; FURLANI, C. E. A.; SILVA, R. P.; GERLACK, J. R.; CORTEZ, J. W.; GROTTA, D. C. C. Decomposição de culturas de cobertura no sistema plantio direto, manejadas mecânica e quimicamente. Engenharia Agrícola, v. 27, n. 1 p.194-200, 2007

25.ROMAN, E. S.; VELLOSO, J. A. R. O. Controle cultural, coberturas mortas e alelopatias em sistemas conservacionistas. In: EMBRAPA. Centro Nacional de Pesquisa de Trigo. Plantio direto no Brasil. Passo Fundo : Aldeia Norte, 1993. p. 77 84

26.ROSOLEM, C. A; CALONEGO, J. C.; FOLONI, J. S. S.. Lixiviação de potássio da palha de espécies de cobertura de solo de acordo com a quantidade de chuva aplicada. Revista Brasileira de Ciência do Solo, v. 27,n. 2, p. 355-362, 2003.

27.RUEDELL, J. Plantio Direto na Região de Cruz Alta. Cruz Alta: FUNDACEP/FECOTRIGO, 1995. 134 p.

28.SODRÉ FILHO, J.; CARDOSO, A. N.; CARMONA, R.; CARVALHO, A. M. Fitomassa e cobertura do solo de culturas de sucessão ao milho na região do cerrado. Pesquisa Agropecuária Brasileira, v. 39, n.4, p.327-334, 2004.

29. TIMOSSI, P. C.; DURIGAN, J. C; LEITE, G. J. Eficácia de glyphosate em plantas de cobertura. Planta Daninha, v. 24, n. 3, p. $475-480,2006$.

30.VAN SOEST, P. J. Nutricional ecology of ruminant. New York: Cornell University Press, 1982. 373p.

31.VICTÓRIA, R. L.; PICCOLO, M. C.; VARGAS, A. A. T. O ciclo do nitrogênio. In: CARDOSO, E. J. B. N.; TSAI, S. M.; NEVES, M. C. P. (Coord.) Microbiologia do solo. Campinas: Sociedade Brasileira de Ciência do Solo, 1992. p.105-120.

Recebido em 07/06/2010 Aceito em 05/12/2011 